\title{
A Way Out for EFL Education at the Tertiary Level under the Context of Internet Plus
}

\author{
Xiaolong Feng \\ Zhejiang Yuexiu University (ZYU), Shaoxing 312000, Zhejiang Province, China
}

\begin{abstract}
The application of modern information technology in College English teaching not only makes the teaching methods modernized, diversified and convenient, but also transform its teaching ideas, teaching modes and learning conditions. This paper analyzes the major challenges in teaching and learning faced by EFL education at the tertiary level under the background of internet plus foreign language education, including decline of college students' motivation and engagement in English learning, transition problems from online learning to offline learning, and teachers' lack of information technology competence. To address the above listed challenges, this paper puts forward corresponding solutions to better meet the requirements of the "Internet plus" era.
\end{abstract}

Key words: Internet Plus; College English; Information Technology Literacy

Publication date: April, 2021; Publication online: 30 April, 2021

*Corresponding author: Xiaolong Feng, fengxiaolong1309@sina.com

\section{Background}

The $13^{\text {th }}$ Five-Year Plan of National Education issued by The State Council of the People's Republic of China advocated the concept of "Internet plus education", making every effort to deeply integrate information technology with education and teaching; making good use of high-quality digital resources in various ways, such as flipped classroom and blended teaching to form a new model of ubiquitous learning model that combines online and offline learning ${ }^{[1]}$. College English Teaching Guidelines (2020) also proposed that College English should give full play to the main role of modern educational technology, especially modern information technology in English teaching, and vigorously promote the deep integration of Internet information technology and course teaching ${ }^{[2]}$. In response to the above requirements, the blended teaching and learning model has been in its full swing in EFL education at the tertiary level, benefiting both teachers and students. Nevertheless, due to shortcomings and deficiencies of online teaching, there are many factors influencing EFL teaching quality, to name only a few: the teaching quality is difficult to guarantee, teacher-student interaction is not enough, the information technology support needs to be strengthened, the teachers' information literacy and the application ability of information teaching need to be improved, students lack autonomous learning ability, etc. In the following part, this paper analyzes three major challenges in teaching and learning faced by EFL education at the tertiary level under the background of internet plus.

\section{Challenges}

\subsection{Decline of college students' motivation and engagement in English learning}

With the continuous penetration and influence of educational informatization, especially intelligent technology, "personalized" and "self-help" concepts are reshaping Education ${ }^{[3]}$. This kind of learning mode puts forward higher requirements for students' learning motivation and autonomous learning ability. The post-90s and post-00s, known as "digital natives", grow up with the Internet. Through the Internet, students have greater autonomy and selectivity in the process of English learning, but at the same time, it brings new challenges to stimulate students' learning motivation. Study shows that the decrease of motivation in English learning is common among liberal arts students, with $65.3 \%$ of the subjects claiming that their motivation in English learning has decreased ${ }^{[4]}$. Another challenge lies in students' online learning engagement. Being accustomed to learning in the teaching entity space and face-to-face 
communication and interaction with teachers and peers, college students' online learning engagement is facing an unprecedented challenge due to lack of teachers' effective supervision as well as campus environment and classroom learning conditions.

There may be a combination of factors which contribute to decline of college students' motivation and engagement in English learning. In the first place, for a large number of EFL learners, English learning is predominantly driven by passing College English Test 4/6. This instrumental motivation caused students' lack of enthusiasm or aimless once passing the exam. However, this is far from enough in the new era. According to College English Teaching Guidelines, the objectives of college English teaching are to develop students' English application ability, cross-cultural communication awareness and communicative competence, at the same time to develop their autonomous learning ability, to improve comprehensive cultural literacy, to enable them to use English effectively in their study, life, social interaction and future work, and to meet the needs of national, social, school and personal development. Therefore, the traditional examination-oriented EFL education has been completely unable to adapt to the "Internet plus" era. With the rapid development of global integration, high technology, and the continuous promotion of Belt and Road, higher requirements are put forward for college English courses with a higher aim to develop college students' information technology literacy and critical thinking ability, and pay attention to the cultivation of college students' cross-cultural consciousness and international humanistic feelings.

Secondly, given the fact that autonomous learning ability is one of the basic requirements for college students' online English learning, some students are often unable to maintain their learning motivation due to their strong dependency on their teachers, low autonomous learning ability, lack of effective supervision and differentiated instruction from the instructors, as well as emotional deficiency. As a consequence, they show a low or shallow input level of English learning, leading to a decline in motivation with time going by.

\subsection{Transition problems from online learning to offline learning}

Li (2019) analyzed concrete problems of transition from online learning to offline learning in three aspects as instructional content, instructional procedures and instructional assessment ${ }^{[5]}$. The major findings are as follows. "With regard to instructional content, difference between difficulty of online learning and offline learning is indistinguishable without following the mode of 'easy online $\&$ difficult offline'. With regard to instructional procedures, teacher's interaction with students in online learning is less than that in offline learning. With regard to instructional assessment, students are less likely to receive evaluation from the teacher like what they receive in offline learning." ( $\mathrm{Li}$, 2019, v-vi)

\subsection{Teachers' lack of information technology competence}

The advent of the Internet plus era has provided a new teaching method, learning mode and abundant teaching resources for foreign language teaching. The integration of information technology and classroom has produced a new teaching mode - the blended teaching mode combining Internet and English entity classroom. This mode requires the full use of information technology and network resources in English teaching, as well as the cultivation of students' ability of inquiry and autonomous learning in order to make English teaching and learning more flexible and personalized. All of these put forward higher requirements for foreign language teachers. College English teachers should keep pace with the times, constantly enhance the awareness, knowledge and ability of using information technology, and use scientific information methods and means to quickly and accurately grasp the research results of disciplines and related fields, so as to better adapt to the trend of deep integration of information technology with foreign language education. But in the actual teaching, many English teachers lack the necessary information technology skill training. In the process of online teaching, they simply transplant the traditional classroom teaching to online teaching, and do not make full use of the advantages and characteristics of online teaching to carry out reasonable teaching design and efficient teaching activities.

\section{Solutions}

\subsection{Foster students' motivation and engagement in EFL class}

To make students motivated and engaged in EFL class, both online and offline, the top priority is to enhance their autonomous learning ability. Autonomous learning ability requires students to have their own learning goals and independent thinking ability in college English class, not limited to what teachers speak in class or rely too much on teachers, on the other hand, to make rational use of network 
resources and smartphones for autonomous learning. To achieve this goal, EFL teachers should provide students with a variety of online and offline services and resources, together with scaffolding instruction, so that students perceive that the teacher is concerned about their online and offline school situation, which can reduce their psychological anxiety and uneasiness caused by maladjustment to blended learning. In this way, students will gradually become strategic learners with positive learning motivation in both online and offline learning.

Secondly, EFL teaching should start from the real problems or students' real life to stimulate students' internal motivation to solve problems by increasing the feasibility and authenticity of learning content. EFL teachers should also help students discover their own advantages and potential opportunities for English learning through internet plus reform, and then reflect on how to jointly construct these advantages and opportunities and associate them with students' future career planning to create the most ideal future they want.

Thirdly, creating conditions and environment to stimulate students' learning motivation, respect students' differences in learning style and learning ability, let students moderately control their own learning, and stimulate students' creativity and initiative in the process of English learning.

Fourthly, students should be allowed to set their own learning goals and plans and create a positive expectation. EFL teachers should guide students to set their own learning goals according to the teaching goals or tasks of each unit, and do self-reflection at the last five minutes of each class to see if they have achieved their own small goals. In this way, students' self-efficacy will be enhanced through achieving each small goal they set by themselves.

Fifthly, providing students with more flexible, collaborative and multi-mode learning activities with the aid of smart technology, such as smart classroom and mobile phone so that students are more interested in the course content and have a sense of satisfaction. To make students have the desire to continue learning English, learning must be able to produce a sense of satisfaction. One effective way to achieve this is planning lessons which are differentiated through content, process, or product ${ }^{[6-7]}$ according to students' readiness, interest, or learning profile through a variety of instructional strategies, such as flexible grouping, alternative assignments, learning stations, etc ${ }^{[6]}$.

\subsection{Optimizing the transition from online learning}

\section{to offline learning}

The optimization of the transition from online learning to offline learning can be divided into three phases.

\section{Phase one: before class}

Before class, EFL teachers should investigate and analyze students' learning needs, learning styles, knowledge gap, English proficiency levels, motivational belief, interests, course objectives, online learning environment, etc., and take these factors into consideration in lesson planning. Then teachers release teaching contents and preview tasks on the elearning platform. Students are supposed to learn autonomously through textbooks and e-learning resources and courseware on the platform. Problems encountered in the self-learning process can be asynchronously negotiated, cooperated and exchanged with teachers and peers anytime and anywhere through the e-learning space. In this process, teachers need to monitor and track each student's online learning process, which can help carry out subsequent personalized analysis and provide students with personalized resources or services.

\section{Phase two: during class}

To begin with, EFL teachers should design a quiz or Q\&A session to check whether students have finished the preview task or not. Then teacher explains the key and difficult points according to the questions raised by the students in the preview, and adjusts the teaching content accordingly. What is recommended here is that after students obtain language knowledge through online autonomous learning, EFL teachers can design various activities (such as debate, team project, game, Socratic discussion, presentation, etc.) to provide opportunities for students to apply the language knowledge into practice. For example, EFL learners can establish interest oriented learning community, and choose topics of mutual interest to carry out autonomous inquiry learning ${ }^{[8]}$.

\section{Phase three: after class}

Taking advantage of internet plus as a driving force, EFL teachers can establish an evaluation system characterized by the combination of online assessment and offline assessment, formative assessment and summative assessment, dynamic assessment and static assessment, standard routine evaluation and random flexible evaluation, so as to ensure the authenticity, objectivity and real-time of the whole academic evaluation. On the other hand, EFL teachers should guide students to develop the habit of self-supervision and selfreflection on their own learning. In addition, teachers should 
provide timely and immediate feedback on students' online and offline learning, promote effective communication and benign interaction between teachers and students, and construct a blended learning community among teachers, students and peers.

\subsection{Enhance EFL teachers' teaching literacy and information literacy}

Teaching literacy is an aspect of teachers' literacy, focusing on teachers' teaching knowledge, teaching ability, teaching strategies, teaching activities and teachers' behavior and roles in the classroom. It covers at least the following three aspects: firstly, to master the relevant professional knowledge of teaching, including the knowledge of 'how to teach', such as teaching environment, curriculum, teaching design, teaching mode and method, classroom management, teaching evaluation, and so on, as well as the knowledge of 'how to learn', such as students' needs, characteristics, differences, motivation, etc.; secondly, to have the ability and skills to apply the professional knowledge of teaching to teaching practice activities; thirdly, to understand the theory, belief, principle, value, idea behind teaching activities or teaching methods, and to have the ability to reflect. Study shows that some English teachers in colleges and universities have not systematically studied the theory of foreign language education, and lacked theoretical guidance. Therefore, the improvement of teachers' teaching literacy is the basis to ensure their teaching ability. There are many ways to improve teachers' teaching ability, but curriculum construction is undoubtedly one of the most effective means. The core of curriculum construction is curriculum design. Taking the syllabus, teaching activities and teaching evaluation as the starting point, the detailed design of the course can effectively improve the classroom teaching and improve the teaching quality.

With regard to information literacy, to meet the requirements of the 'Internet plus' era, College English teachers need to keep pace with the times, establish the value orientation of lifelong learning, integrate information of online courses into the teaching with the help of network technology, promote the reform of College English classroom teaching, and optimize teaching design. Through project based learning, task based learning, heuristic teaching method, Socratic problem discussion, together with the use of highquality digital resources, such as flipped classroom, micro class, MOOCS and other teaching activities, EFL teachers should innovate and practice online teaching mode to better achieve the goal of the course. In terms of online course design, the principle of standardization and conflict should be followed, which means online class should have certain standards, but not necessarily uniform, otherwise it will stifle the creativity of teachers. Reverse design is recommended: starting from learning objectives, then adjust the teaching goal, select the evaluation methods, and implement the teaching strategy. In terms of how to integrate technology into classrooms, EFL teachers can refer to SAMR model (Substitution, Augmentation, Modification, Redefinition) developed by Dr. Ruben R. Puentedura. As for teachers' role in online teaching, there should be a transformation from the traditional 'sage' in the classroom to 'guide' and 'scaffolding' in the internet plus era. As for the assessment of online class, EFL teachers should improve evaluation literacy by providing students timely feedback and adopting diversified evaluation modes, such as combination of online assessment and offline assessment, formative assessment and summative assessment, dynamic assessment and static assessment, peer assessment and self assessment. As far as the network social relations are concerned, it is necessary to realize the positive interaction among schools, parents, teachers and society.

On the other hand, the author believes that young teachers should become the digital leaders of higher education, ponder over how to effectively integrate information network technology and smart phones with college English teaching, and dare to innovate and explore new models of College English classroom teaching. In addition, we should correctly guide students to make rational use of smart phones and digital resources, so that these digital resources can become a booster to promote students' English learning instead of causing them to indulge in it. Finally, the author thinks that young teachers should take the initiative to help those old teachers who are used to traditional teaching methods or unwilling to accept new things, and give them more help from the level of digital technology, so that they can also reap the benefits and convenience from digital teaching.

College English teachers should also strengthen the relevant professional skills of foreign languages and literature, including foreign literature, foreign linguistics and applied linguistics, comparative literature and cross-cultural research, translation and country and regional research, and continue to learn to improve their English language proficiency and cross-cultural literacy in combination with the instrumental and humanistic nature of college English courses. At the same time, in the face of the talent training needs of different 
disciplines or specialties, college English teachers should think about and respond to the new requirements and new propositions.

\section{Conclusion}

The integration of education and technology has increasingly become a prevalent trend of China's education reform, and will play a more vital role in the future development of education. The advent of the era of Internet plus in higher education in new era have put forward higher requirements for College English teaching and learning. In face of the challenges, much effort should be focused on rational utilization of information technology and optimization of the transition from online learning to offline learning through a variety of strategies and the joint efforts of the school, teachers and students.

But one fact we can not ignore is that no matter how advanced information technology is, it can not and will not replace the status of teachers in education. Therefore, under the current trend of blended learning integrated face-to-face instruction and online teaching in EFL education, we should keep a cool head and thoroughly reflect on whether the integration of technology elements really solves the problems we encounter in foreign language teaching. Instead of blindly following the trend, students' characteristics and individualized needs should always be taken into account.

\section{References}

[1] National Development and Reform Commission. The 13th Five-Year Plan of National Education [OL]. 2017 $<$ http://www.moe.gov.cn/jyb_xxgk/moe_1777/moe_1778/201 701/t20170119_295319.html>
[2] The National Foreign Language Teaching Advisory Board under the Ministry of Education. College English Teaching Guidelines (2020). Higher Education Press, 2020.

[3] Tian Rui, Xiong Ziyin \& Normand Romuald. Challenges and Solutions in Teaching and Learning in the COVID-19 Crisis: Analysis and Reflection based on OECD's "A Framework to Guide an Education Response to COVID-19 Pandemic of 2020" [J]. Journal of Distance Education, 2020, 38(04): 3-14.

[4] Wang Zhanfeng. Study on the English Learning Demotivation of Liberal Arts Students in Applicationoriented University [J]. Journal of Wuyi University, 2020, 39(4): 48-53.

[5] Li Meng. A Study on Transition from Online to Offline in Blended Learning of College English [D]. Nanjing University of Aeronautics and Astronautics, 2019.

[6] Shaver, B. K., \& Hunter, A. Differentiated Instruction in the English Classroom: Content, Process, Product and Assessment. U.S.: Heinemann Educational Books, 2003.

[7] Tomlinson, C. A. How to Differentiate Instruction in Academically Diverse Classrooms (3rd Edition). ASCD, 2017.

[8] Li Zhihe, Zhou Nana, Qin Yifan, Li Ning. Construction of Activity Mechanism of Hybrid Learning Community in Network Learning Space[J]. China Educational Technology, 2019(09):104-111. 